\title{
Nas pegadas da história: tracejando relações entre deficiência e sociedade
}

\author{
Gustavo Martins Piccolo* \\ Enicéia Gonçalves Mendes**
}

\section{Resumo}

Este trabalho objetiva, mediante processo de revisão literária, contribuir para com o entendimento da deficiência como produção social temporal e espacialmente situada. Centra-se sobre o período Medieval na busca de radiografar de que maneira a deficiência era entendida em tal contexto histórico, para tanto, nos valemos dos estudos de Kapler, Minois e, fundamentalmente de Rosemaire Garland-Thompson e sua emblemática obra sobre os freak shows, textos estes que nos permitem escovar as relações entre deficiência e sociedade a contrapelo, possibilitando o despir do suposto de aludida condição como dependência ou limitação, cuja consecução se materializa como obra do capitalismo e não de toda a história da humanidade conforme tencionam nossos apontamentos.

Palavras-chave: Deficiência. Freak Shows. Diferença.

\section{In the footsteps of history: tracing relationships between disability and society}

\begin{abstract}
This paper aims, through a process of literature review, contribute to the understanding of disability as social production temporally and spatially located. It focuses on the Medieval period, with the objective explain how the disability was understood in this historical context, to do so, we make use of studies Kapler, Minois and fundamentally Rosemaire Garland-Thompson and his work on the freak shows. These texts allow us to brush the relationship between disability and society against so unusual forms, allowing the critical of the alleged condition as aforesaid limitation or dependence, whose achievement is embodied as a work of capitalism and not the entire history of humanity as they intend our notes.
\end{abstract}

Keywords: Disability. Freak Shows. Difference.

\footnotetext{
* Doutorando em Educação Especial e mestre em Educação pela Universidade Federal de São Carlos (UFSCar). São Carlos, São Paulo, Brasil.

** Pós-Doutorado SORBONNE- UNIVERSITE PARIS V-RENE DESCARTES. Doutora em Psicologia pela USP (Universidade São Paulo). Professora adjunta da UFSCar. São Carlos, São Paulo, Brasil.
} 


\section{Introdução}

Em seu "Da preguiça como método de trabalho" Mário Quintana (1987) reitera que os dias chuvosos e nublados são ótimos para um repensar dos temas que rondam nossa existência. E foi exatamente em um destes dias chuvosos que me pus a pensar sobre o porquê de meu interesse quanto à temática da deficiência. Lembro como se fosse hoje da leitura de Rosadas (1991) realizada há quase uma década, e seu destaque explícito dos deficientes como sujeitos passivos e do contínuo remomerar a Esparta e Atenas para explicar a história dos mesmos. A Esparta guerreira e que valorizava a dança, a ginástica, a perfeição do corpo e sobre cujo solo pátrio a deficiência era eliminada já ao nascimento constituía uma imagem figurativa que me perturbava sobremaneira. Sobre os períodos antecessores ao domínio grego nada me recordo de ter lido no tracejar da experiência da deficiência, assim como no período medieval.

Qual o motivo deste silêncio? Será mesmo que tais épocas não têm nada a nos dizer ou mostrar? Porque a imensa maioria dos trabalhos históricos sobre a deficiência principia cifrando os mores gregos tal qual um conhece-te a ti mesmo? É necessário voltar aos gregos para entender tal constructo?

Se é necessário esta volta, que não nos parece ser o caso, qual a razão de quase nada ser escrito sobre os corpos que hoje classificamos como deficientes na Idade Média? Não estaremos nós diante de um processo insidioso que tenta demarcar a deficiência sob uma historicidade linear que acaba por apagar sua composição como produto social? Colocado estes elementos, torna-se inegável a necessidade de procurarmos nos ardis de outros frascos caminhos que edifiquem entendimentos não uniformes ou homogêneos sobre os corpos vistos como deficientes.

\section{Há mais história do que aquela que nos é contada}

Não constitui qualquer novidade a afirmação, como pontua Stiker (2006, p. 24), de que a figura da diferença entendida hodiernamente como deficiência esteve historicamente presente nas mais diversas sociedades já noticiadas, pois "onde quer que tenha havido relatos efetivos de corpos humanos em coletividades sociais podemos também pressupor dá existência de corpos humanos em desvio, enfim, corpos excepcionais, diferentes, anormais". Por um exercício de lógica podemos considerar, nestes termos, a deficiência como uma constante e não um desvio na história da humanidade. Contudo, tal presença não pode ser utilizada a fim de demarcar um suposto processo de naturalização, na medida em que, apesar de existir nas mais diversas épocas, continua a se tratar de um fenômeno profundamente histórico que varia em termos de amplitude e incidência em contextos sociais distintos, pois conforme retrata Omote (2004, p. 289).

A história da Humanidade revela, desde os tempos remotos, as mais variadas formas de se lidar com determinadas diferenças, alvos de alguma atenção especial, 


\begin{abstract}
seja de temor e medo, seja de admiração e veneração. As mais variadas diferenças receberam os mais variados tratamentos no decorrer dos milênios. Condições que eram alvos de profunda abominação, podendo até levar o seu portador a formas extremas de exclusão ou de eliminação, podem, em outros tempos, tornar-se alvos de afeição e simpatia. Outras condições podem ser repudiadas em algumas comunidades e aceitas em outras, na mesma época, recebendo interpretações e eventualmente designações diferentes.
\end{abstract}

Destarte, toda e qualquer diferença, como o é a deficiência, pode ser vista sob o prisma ontológico da produção social. Até por esta anátema é preciso ir além da afirmação da mesma como criação histórica. Ora, isso não diz absolutamente nada ou nos revela muito pouco. Necessitamos destacar suas variações temporais, posto que modos distintos de produção social engendrem distintas silhuetas do que é visto como diferente. Evidente que esta tarefa se mostra irrealizável no espaço de um artigo, uma vez que como aponta LéviStrauss (1993, p. 340) "todas as sociedades humanas têm atrás de si um passado que é aproximadamente da mesma ordem de grandeza". Resta-nos então assumirmos o risco de pensarmos o aludido tema de forma diferente a lógica perpetrada pelo saber moderno, cuja consecução objetiva obnubilar as especificidades históricas de sua configuração.

Esta é a primeira e mais importante tarefa deste trabalho, impregnar a deficiência de meandros históricos. Apenas então podemos redargui-la sob outro lineamento. Se a lógica atual é apagar a historicidade dos fenômenos humanos, a nossa, consiste justamente no oposto, impregnar de história o supostamente dado e natural, biológico e eterno, vértices estes hegemonicamente utilizados no processo exegético de apropriação das complexas relações que envolvem deficiência e sociedade, presentes desde o estabelecimento das primeiras comunidades humanas, contudo, contínua e inescrupulosamente apagada da história que nos é contada pela via escrita. É preciso recobrar o passado com os olhos de quem nele introduz algo novo. Recuperar épocas e fenômenos esquecidos ou convenientemente não contados pela história oficial. Se embrenhar nos interditos e no insólito. Escovemos a História a contrapelo.

Ao tentar materializar tal ato, todavia, é fundamental não perder de vista que em todas as sociedades, conforme atesta Marx (1977, p. 172) "é uma produção específica que determina todas as outras, são as relações engendradas por ela que atribuem a todas as outras o seu lugar e sua importância, é uma luz universal onde são mergulhadas todas as outras cores e que as modifica no seio de sua particularidade". Desde o estabelecimento da modernidade propriamente dita, esta luz universal é dada pelo sistema capitalista de produção. Nenhum fenômeno social foge plenamente de sua influência e a seu universalismo, que efetivamente adentram os mais distantes recônditos do globo. Com a deficiência não é diferente. A ascensão do capitalismo a sistema hegemônico transforma de maneira radical a maneira como esta é encarada, 
passando a ser percebida como falha, incapacidade, ineficiência, atributo que estabelece uma relação de passividade para aqueles que a apresentam. Mas será que esta representação corporifica sua história universal?

\section{Como posso te chamar Quasímodo? E ele responde. Monstro}

O subtítulo compõe uma passagem da obra "O Corcunda de NotreDame", escrita por Vitor Hugo (2006) e tornada clássico universal da literatura. Sua utilização é proposital, posto que com ela queiramos destacar um suposto que tem passado despercebido perante as retinas dos estudiosos sobre a deficiência, qual seja: anteriormente a Idade Moderna o deficiente era tido como monstro. Este era seu estigma, sua marca. Não havia deficientes porque simplesmente a etimologia sequer existia à época. Uma mostra clara deste apontamento pode ser dada quando investigamos os espetáculos circenses estruturados sob a teatralização das diferenças. Acerquemo-nos destas relações.

Desde o Egito imperial se notava a existência de alguns espetáculos envolvendo corpos definidos como bizarros e grotescos a fim de entreter o público, dentre os quais se encontravam os aleijados, cegos, surdos, dentre outros, hoje rebatizados de deficientes físicos e sensoriais. Tal prática se manteve constante na Grécia Antiga e em Roma, declinando após a queda romana e ressurgindo com vigor na Baixa Idade Média, adentrando ao véu da modernidade. Assim, nos parece evidente que dentre os hábitos mais comuns manifestos pelas sociedades certamente um deles é teatralização das diferenças. O corpo considerado diferente em demasia era ridicularizado e utilizado como espaço preferencial de chacota e comédia sobre a vida pública e privada, funcionando como uma espécie de anestésico social.

Estes espetáculos pareciam feitos no sentido de possibilitar o tecer das mais diversas caricaturas sobre tudo aquilo que a humanidade queria longe de si. A máxima contida em sua ideia consiste no jargão 'nada é tão ruim que não possa ser piorado'. Como aponta Platão (1988), "se a condição do escravo era indigna ao menos este era perfeito fisicamente. Pior se seu corpo apresentasse os aspectos daqueles miseráveis expostos em teatros públicos. Aí sim teriam que se lamentar". Esta citação fornece uma mostra de que a vida para algumas pessoas com deficiência estava longe de passar em brancas nuvens na Antiguidade. Como eram denominados etimologicamente tais corpos e pessoas? Monstros. E como pontua Foucault (2000, p. 61) "o monstro humano combina o impossível e o interdito". De acordo com Júnior (2006, p. 8), dentro da categoria monstros se encontram presentes "(...) os cegos, zarolhos, corcundas, coxos ou que têm seis dedos na mão ou nos pés, ou menos de cinco, ou juntas unidas, ou braços muito curtos ou não tem braços, ou não tem pernas, ou o nariz muito encravado ou os lábios grossos e invertidos ou qualquer outra coisa contrária à natureza".

O corpo definido como monstro propicia os sentimentos mais diversos na sociedade, desde o riso e a chacota, até o medo e o encantamento. De acordo 
com Claude Kappler (1994), esses seres incríveis carregam a marca explícita de algo que está fora da ordem, além do natural e conhecido.

Nesse sentido, os monstros abriam um leque de possibilidades sobre o universo humano que gerava concomitantemente um sentimento de sedução e profundo receio. Queria se estar perto e longe concomitantemente.

Definir etimologicamente monstro não é das tarefas mais fáceis. Rosemaire Garland-Thompson (2001) destaca que tal palavra tem sua origem no latim monstra, significando a prática de mostrar ou apresentar algo. Cohen (2000), embora por outros caminhos, chega a uma definição similar, na medida em que para ele o termo deriva do latim monstrum, ou seja, aquele que revela e adverte. Independentemente da raiz etimológica, monstro adquire o significado daquele que expõe algo, seja uma revelação divina, as infinitas e enigmáticas possibilidades da natureza ou mesmo aquilo que o homem poderia vir a ser. Como pontua Júnior (2006, p. 8)

[...] não é apenas o terror que a figura monstruosa provoca. É também fascínio, encanto, dúvida, fonte de curiosidade e desejo. Por isso, desde a antiguidade até pelo menos o século $\mathrm{XVI}$, os monstros no Ocidente também eram classificados entre as "maravilhas" ou "prodígios" do mundo e podiam evocar tanto o medo quanto a risada através de suas formas exageradas, assustadoras ou ridículas. Mais que uma simples imagem da ira divina ou mesmo da insanidade sexual dos homens, estes seres eram, antes de tudo, manifestações do poder incognoscível do mundo sobrenatural.

Como algo que expõe, exibe e manifesta sua característica fundamental é dada pelo recorte da aparência física. Logo, o foco da diferenciação entre os corpos grotescos definidos como monstros e os normais reside na estrutura orgânica e material e não no caráter moral do humano. A aparência física define quem se enquadra neste conceito e quem não faz parte dele. Não por acaso, o lendário Quasímodo foi definido como o Papa dos Loucos (monstro por excelência) devido a sua corporeidade distinta e não usual.

Fora eleito o Papa dos Loucos. - Aleluia! Aleluia!" - gritava o povo de todos os lados. Era, com efeito, uma carranca maravilhosa a que, naquele momento, resplandecia pela abertura da rosácea. Não tentaremos dar ao leitor a ideia do nariz tetraédrico, da boca em ferradura, do pequeno olho esquerdo obstruído pela sobrancelha ruiva e emaranhada enquanto o olho direito desaparecia completamente sob uma enorme verruga, dos dentes desordenados, falhados aqui e lá, o esgar, aquela careta medonha, era o seu próprio rosto. Uma cabeça formidável, com uma cabeleira ruiva eriçada; entre os ombros, uma protuberância enorme que, com o movi- 
mento, percebia-se pela frente; um sistema de coxas e de pernas tão singularmente descambadas que apenas se podiam aproximar pelos joelhos e, vistas de frente, pareciam duas lâminas recurvas de foices, unidas pelo cabo, pés largos, mãos monstruosas; e, com toda essa deformidade, não sei que porte temível de vigor, de agilidade e de coragem (...) - É Quasímodo, o sineiro! É Quasímodo, o caolho! Quasímodo, o cambaio! Aleluia! Aleluia!. (VITOR HUGO, 2006, p. 60)

A ascensão do cristianismo produz transformações no conceito de monstros. Em razão de os homens serem encarados como filhos e semelhantes a Deus, cuja imagem porta perfeição nos traços, aqueles com corpos diferentes foram considerados como não semelhantes ao criador, portanto, obras do pecado. Neste sentido, como aponta Gil (1994), em seu emblemático "Monstros", sob a prescrição do maniqueísmo característica da sociedade de outrora os mesmos apenas podiam ser considerados criaturas malignas. Inexistiam meios termos e o espaço do entre. Se até o século XIII o corpo monstruoso era encarado mais pelo lado cômico do que propriamente malfazejo, isto se inverte de maneira sutil desde esta data, período no qual as maravilhas e prodígios já não são mais encarados como ambíguos, mas, sim, como seres maléficos e essencialmente perigosos, raciocínio de cujo perfilhar se encontra em contraposição ao descrita por Pessotti (1984), para quem tais pessoas passaram a ser durante a Idade Média "lês enfants Du bom Dieu".

Não, não o eram. Basta lembra a Bíblia, pedra angular dos preceitos alavancados pelo cristianismo. De maneira explícita percebemos na Bíblia a associação da deficiência com o pecado. E de quem era a obra do pecado? Não causa estranho, portanto, que dos 22 milagres de cura e exorcismo feito por Jesus, 12 estão diretamente relacionados ao transcender de condições hoje rotuladas como deficiências físicas e sensoriais. Talvez o exemplo mais cristalino desta associação seja traçada na cura do paralítico de Betesda, no qual Jesus ao perdoar seus pecados diz ao mesmo "Levanta-te e anda". Abrolha neste tempo, pela primeira vez na história, o estabelecimento de uma rede de proteção derivada da moral cristã a tais pessoas e corpos, a qual colocava como inaceitável a prática espartana da exposição como forma de eliminação. Este fenômeno foi singularmente descrito por Pessotti (1984, p. 48), para quem

Agora a ética cristã reprime a tendência a livrar-se do deficiente através do assassínio ou da "exposição", como confortavelmente se procedia na Antigüidade: o deficiente tem que ser mantido e cuidado. A rejeição se transforma na ambigüidade proteção-segregação ou, em nível teológico, no dilema caridade-castigo. A solução do dilema é curiosa: para uma parte do clero, vale dizer, da organização sociocultural, atenua-se o "castigo" transformando-o em confinamento, isto é, segregação (com desconforto, algemas e promiscuidade), de modo tal que segregar é exercer a caridade pois o asilo garante um 
teto e alimentação. Mas, enquanto o teto protege o cristão as paredes escondem e isolam o incômodo ou inútil.

Destarte, inexiste contradição entre malignidade e proteção. Protegia-se também para se afastar e evitar o contato, destarte, não causa espanto que os leprosários se situassem nas zonas limítrofes da cidade. Assim, como aponta Júnior (2006, p. 11), "com a dominação da ideologia cristã na Europa, a estranheza do fantástico vai ser substituída em grande parte pelo temor do maligno". Quanto mais avançamos na história maior é a relação que se faz entre os monstros como símbolo do maléfico graças à identificação da deformidade com o demônio.

Efetivamente a deficiência não passava despercebida nestes tempos históricos e a deformidade do corpo era vista em termos sinonímicos a deformidade da alma. Prova disso está em que, de acordo com Minois (2003, p. 227), mesmo o famoso bobo da corte ou bufão, supostamente classificado como deficiente intelectual, representava "a pessoa mais feia ou fisicamente estranha da região. É escolhido por sua deformidade, sendo que os reis faziam uma verdadeira coleção de anões e de aleijões para trocarem entre si". Quanto mais corporeamente diferente, mais expressava a vida fora dos eixos e encantamento despertava. Quando os mesmos não eram encontrados naturalmente, de acordo com Nazário (1998, p. 46), poderiam ser criados, assim, “(...) em algumas localidades como a Boêmia, crianças tinham os lábios cortados, as cabeças comprimidas ou eram fechadas em caixotes para que os ossos calcificassem e os músculos atrofiassem de maneiras disformes".

Devido a sua deformidade, primeiro física, e apenas supostamente intelectual, o chamado bobo passava a viver na corte para divertir os reis e a todos que frequentassem este espaço, logo, eram alvos constantes de ofensas, chacotas e de toda sorte de desprezos por serem vistos como a encarnação daquilo que há de mais ridículo, estúpido e maléfico no ethos humano. Parcela significativa do universo do cômico e risível estava centrada sobre esta figura. Contudo, como aponta Júnior (2006, p. 13), este personagem assumia durante o medievo um papel ambíguo derivado de sua própria condição social, na medida em que

Eram os únicos naquela estrutura social que podiam criticar e ridicularizar a todos indiscriminadamente, inclusive o próprio rei, rebaixando os detentores do poder, invertendo as hierarquias e dando voz a desejos proibidos. Como duplo grotesco do rei, todas as palavras proferidas por alguém monstruoso e repulsivo só podia realmente fazer rir. (...) Pela via da risada, o bobo expunha a verdade, que mesmo sendo agressiva, era perdoada por ser anunciada por um "louco". Da mesma forma, esta capacidade de ver e expressar as idéias e desejos não confessos conferem a estes seres desen- 
gonçados uma íntima associação com os poderes mágicos e sobrenaturais. Sendo um monstro, tem acesso às "verdades" ocultas dos homens.

De maneira paradoxal, estas pessoas situavam-se no extremo limite da exploração e da liberdade de opinião, da privação e da expressão. Destacase, por conseguinte, um papel muitas vezes impensado, a citar, dos monstros, muitos dos quais seriam definidos aos nossos olhos por deficientes, como primeiros e únicos críticos das sociedades de côrte. Se muitas das principais críticas sociais de outrora passavam pelo bobo, conforme pontua Minois (2003), constitui-se quase que como movimento lógico ver a deficiência nesse espaço sob outra perspectiva da comumente aceita. A crítica fervilhava nos poros destes personagens vistos como monstros, cujo papel transcendia em muito a mera distração popular a eles conferida.

Mas não apenas no insólito espetáculo medieval da teatralização das diferenças podemos visualizar um papel distinto conferido as pessoas com deficiência se comparada aos rótulos de passividade e dependência empregue pelos mores modernos. Para Finkelstein (1980), pensador emblemático na historiografia da deficiência britânica, a Idade Média representa um ponto de inflexão em sua relação com as corporalidades definidas como distintas se comparada a Antiguidade grega e a Idade Moderna. Isto porque, nesse período histórico, via de regra, a diferença expressa pela deficiência não se encontrava segregada da sociedade. Devido a pouca complexidade do trabalho, quase todos os deficientes eram incorporados "naturalmente" na realização de tais atividades, elemento que permitia um maior controle sobre suas próprias vidas, além de reconhecidamente serem vistos como contribuintes no processo de produção da riqueza social. Em tal temporalidade, as pessoas com deficiência, caso conseguissem resistir ao nascimento, eram incorporadas imediatamente na cotidianidade dessas relações. Claro que as condições de vida eram extremamente áridas para os deficientes nessa época, mas em um contexto em que a vida era difícil para todos ela não trazia uma desigualdade significativa em razão de sua diferença, sentimento que irá se alterar radicalmente na Idade Moderna, ávida pela castração e reclusão das diferenças.

No entender de Foucault (1997), data desta época o início de um lento, longo e tortuoso processo de disciplinarização dos corpos e uniformização dos desejos, cuja gênese objetivava torná-los úteis e dóceis com vistas à máxima exploração de suas forças objetivas e subjetivas. Os corpos disformes foram submetidos basicamente a três situações não necessariamente autoexcludentes: a) a incorporação em tarefas secundárias nas atividades laboriosas; b) a institucionalização destes em asilos, manicômios, hospitais psiquiátricos, casas de detenção ou em suas próprias residências; c) a transformação de tais corpos em um verdadeiro negócio capitalista mediante sua exibição em eventos pagos, os famosos freak shows, tergiversação mercadológica dos antigos espetáculos de côrte. Como os três primeiros pontos são relativamente bem conhecidos no universo das pessoas que lidam com a temática da deficiência centremos 
por ora nossa atenção na análise dos freak shows, os quais retratam de maneira diáfana a materialização de um verdadeiro comércio e mercantilização das diferenças.

Estas exibições mercadológicas se tornam atrações populares nos primeiros decênios do século XVIII. Em 1723, de acordo com Semonin (1996, p. 70), o Daily Courant, primeiro jornal londrino, cujo editor era o aclamado Daniel Defoe, anunciava um evento que ocorreria no Museu Público de Londres com a seguinte chamada "monstros de todos os tipos vão estar aqui, coisas estranhas ao natural e a como elas acontecem. Imperdível. Compareçam." O que eram esses monstros e coisas estranhas ao natural? Pessoas cujos corpos se apresentavam disformes aos habitualmente encontrados, em termos físicos, raciais ou qualquer outra distinção que fosse considerada importante.

Freak Shows nada mais são do que a espetacularização das supostas anomalias físico-étnico-corpóreas e sua transformação em um grande negócio, não para as pessoas, exploradas em suas individualidades, mas àqueles que detinham os meios de produção do espetáculo. Esta verdadeira mostra de coisas estranhas ao natural, para utilizarmos um termo do Daily Courant, viajou por todo - Ocidente e construiu morada nos Estados Unidos, se firmando como um dos elementos mais característicos da cultura deste país. De acordo com Júnior (2006, p. 17) "com o sucesso causado por estes assombrosos fenômenos, surge toda uma cultura de espetacularização do estranho e anormal como um negócio extremamente lucrativo, que vai estar na raiz da nascente cultura de massas".

Rosemaire Garland-Thompson (1996) pontua que existe uma clara e notória diferença entre os freak shows e os eventos desenvolvidos no medievo por intermédio da teatralização da vida real pelos bobos da corte ou bufões. Ambos, em sua maioria, eram deficientes físicos. Sobre isso parece haver poucas dúvidas. Entretanto, se os chamados bobos da corte eram definidos por um saber basicamente mitológico e religioso, em contrapartida, o mesmo não pode ser dito em relação aos monstros dos freak shows.

Garland-Thompson (1996), em estudo emblemático sobre os freaks, destaca que desde o final do século XVIII, período que marca a consolidação do sistema capitalista, o discurso oficial sobre os corpos essencialmente diferentes ou deformados passa definitivamente das mãos do saber religioso para $o$ campo médico, de explicação laica e secular. De acordo com a referida autora, acompanhado um processo cognitivo e cultural da referida época, os antigos monstros e bufões transformam-se em doentes e degenerados. No dizer de Semonin (1996, p. 69) "(...) a "maravilha" tornou-se erro. Se no século XVII, o gosto por monstros tornou-se uma doença, agora o próprio monstro revela-se não mais que uma patologia".

Recobra sentido, o apontamento de Kassar (1999) de que desde o estabelecer da Idade Moderna no penúltimo quartil do século XVIII e o romper com o modo de pensar tipicamente feudal, o médico passa a se transformar em 
novo árbitro do destino do deficiente. Ele julga, salva e condena se valendo de um corpo de conhecimentos que transforma a explicação da deficiência como problema anátomo-fisiológico, portanto, não mais ligado ao campo teológico e moral. A biologia e o naturalismo se impõem como força determinante, atendendo única e exclusivamente aos desígnios das classes proprietárias com vistas a regular os processos de trabalho. Uma espécie de fiscal do processo de compra e venda da força de trabalho, cujo compósito deveria atender determinados miligramas de normalidade previamente estabelecida. Tal torção também foi acompanha por um processo cognoscitivo, materializado em duas doutrinas filosóficas que efetivamente sustentam o modo de pensar tipicamente moderno alavancado pelo sistema capitalista: o pensamento liberal e positivista, os quais propagam a olhos vistos a perniciosa ideia de um movimento natural e linear realizado no interior das sociedades ocidentais e de cuja validade seria resguardada única e exclusivamente pela ciência. Sua organicidade, fincada nas ideias de ordem e progresso, busca atestar de maneira flagrante que quando da materialização do citado movimento triunfarão apenas os mais aptos e capazes, justamente aqueles que podem se adaptar as novas exigências laboriosas.

Citada contenda envia uma mensagem deveras trágica para as pessoas com deficiência, as quais em uma sociedade que considera o corpo humano como uma máquina (as analogias são inúmeras: o coração é uma bomba; o rim o filtro e o cérebro o dispositivo que controla as ações), vê na condição das mesmas uma prova irrefutável de sua limitação, falha, disfuncionalidade. O oposto da eficiência e produtivo.

A conjunção destes elementos pôs fim ao espetáculo de teatralização das diferenças. Na sociedade do trabalho não havia mais lugar para a balbúrdia e gostos cômicos ou duvidosos. O humano deveria concentrar suas forças na preparação de seu corpo para as atividades laboriosas, com isso, o tempo disponível fora do trabalho também foi visto sob a perspectiva de um instrumento que deveria ser utilizado para recobrar as energias despendidas nesta esfera. Criticavam-se quaisquer excessos e os freak shows materializavam a forma mais abusiva dos mesmos.

Na mesma proporção e velocidade em que os freak shows são contestados e, em diversos locais, proibidos, posto passarem a ser visto pela sociedade como apelativos e vulgares, cresce assombrosamente o número de presídios, hospícios e asilos objetivando cuidar das antigas populações exploradas pelos freaks, assim como de novos elementos que não se encaixam aos padrões impostos pelas atividades laboriosas. Muitos veem nesse direcionamento a instituição de um verdadeiro processo humanizador, já a nós nos parece que tal empreitada se constitui em uma falácia, na medida em que a preocupação com os corpos e mentes disformes não está na integração social propriamente dita, mas, sim, em sua reclusão do universo público, o que pode ser tão ou até mais cruel do que as práticas dos freak shows. Décadas mais tarde, o processo de institucionalização gerado e aclamado por alguns como humanitário passou a ser visto como uma aberração da cultura. 
O corpo de saberes aqui apresentados, embora sinteticamente apresentados, nos permitem contestar a suposta linearidade segregacionista contida intersticialmente na relação entre deficiência e sociedade. Épocas e culturas diferentes estabelecem distintos tropos dialógicos. Esta heterogeneidade é visceralmente afrontada com a elevação do sistema capitalista a forma dominante de produção, fundante do modus operandi moderno.

Desde então, a relação entre deficiência e sociedade tem sido relativamente constante. Tal argumento se encontra presente em Stiker (2006), para quem "(...) embora variável tanto em forma, como no conteúdo e grau em diferentes épocas e contextos durante o período feudal, a percepção da deficiência tem sido relativamente consistente desde a revolução industrial até os dias atuais". Esse suposto metanarrativo também encontra acolhida em autores como Finkelstein (1980), Oliver (1990) e Gleeson (1999), cuja organicidade destaca a necessidade analítica de fundarmos uma espécie de Economia Política da Deficiência, criarmos "O Capital" para a explicação da mesma tal qual Marx fez com o sistema capitalista, na medida em que o corpo com lesões não estaria apto ao regime de exploração da força de trabalho alavancado pelo capitalismo devido à radicalidade que a norma assume na configuração do espaço, ávido por um corpo no qual a força e a destreza física se mostram fatores fundamentais a inserção plena na arquitetura aludida. Logo, se faz fundamental que deixemos em suspenso a interpretação e visualização da deficiência como falta, falha ou propiciadora de uma dependência inequívoca de seu sujeito em relação a outros sujeitos. Urge edificarmos um composto que explique a deficiência em dialética relação com a sociedade, pois como aponta Barnes (2008, p. 383),

[...] las personas designadas como discapacitadas, sea cual sea la definición que se les dé, experimentarán siempre diversos grados de desventajas económicas, políticas y sociales en unas sociedades articuladas en torno al conjunto central de valores capitalistas del esfuerzo individual, la racionalidad económica y la búsqueda del beneficio.

Mudam-se as perguntas e, como consequência, se produzem novas respostas. Destarte, a questão sobre a relação entre deficiência e sociedade quando a abordamos sob o prisma do criacionismo social jamais esteve relacionada à presença ou ausência de diferença, mas sim no escrutínio de quem define a diferença como diferença? De que forma a diferença designa o outro e como suas fronteiras são constituídas, mantidas ou dissipadas? A diferença tem diferenciado lateral ou hierarquicamente? São estas as questões de fundo que necessitam se desenvolver como parte da consecução de uma teoria social da deficiência, a qual rompa radicalmente com os lineamentos médicos de explicação da mesma. Criticar a suposta linearidade da imagem da deficiência ao longo da história é um começo, mas apenas um pequeno passo que precisa percorrer novas trilhas. Esperamos contribuir para tanto. 


\section{Referências}

BARNES, C. La diferencia producida en una década. Reflexiones sobre La investigación emancipadora en discapacidad. In: BARTON, L. (Org.). Superar las barreras de a discapacidad: 18 años de Disability and Society. Espanha: Morata, p. 381-397, 2008.

COHEN, J, J. A Cultura dos Monstros: Sete Teses, in SILVA, Tomaz Tadeu da (Org.). Pedagogia dos Monstros, Belo Horizonte, Autêntica, 2000.

FINKELSTEIN, V. Attitudes and disabled people: Issues for Discussion. nternational Exchange of Information in Rehabilitation/World Rehabilitation Fund, 1980.

FOUCAULT, M. Resumo dos cursos do Collège de France (1970-1982). Rio de Janeiro: Jorge Zahar Editor, 1997.

FOUCAULT, M. As palavras e as coisas. São Paulo: Martins Fontes, 2000.

GARLAND-THOMSON, R, Freakery - Cultural Spetacles of the Extraordinary Body, New York, New York University Press, 1996.

GIL, J. Monstros. Lisboa: Quetzal Editores, 1994.

GLEESON, B. Geographies of disability, Routledge, London, 1999.

HUGO, V. O corcunda de Notre Dame: a verdadeira história de Quasímodo. São Paulo: Companhia das Letrinhas, 2006.

JUNOIR, J, L, L. Monstros, bufões e freaks: riso, medo e a exclusão dos anormais. Caderno dos doutores da alegria. n. 2, 2006.

KAPPLER, C. Monstros, demônios e encantamentos no fim da Idade Média. São Paulo, Martins Fontes, 1994.

KASSAR, M, C, M. Deficiência múltipla e educação no Brasil: discurso e silêncio na história de sujeitos. Campinas: Autores Associados, 1999.

LÉVI-STRAUSS, C. "A Gesta de Asdiwal”, In: Antropologia estrutural II, Rio de Janeiro, Tempo Brasileiro, 1993.

MARX, K. Contribuição à crítica da economia política. Maria Helena Barreiro Alves (Trad.). São Paulo: Martins Fontes, 1977.

MINOIS, G. História do riso e do escárnio, São Paulo, Unesp, 2003.

NAZÁRIO, L. Da natureza dos monstros, São Paulo, Arte e Ciência, 1998.

OLIVER, M. The politics of disablement. Macmillan, Basingstoke, 1990.

OMOTE, S. Estigma no tempo da inclusão. Revista Brasileira de Educação Especial, Marília, v. 10, n. 3, p. 287-308, 2004. 
QUINTANA, M. Da preguiça como método de trabalho. Rio de Janeiro, Editora Globo, 1987.

PESSOTTI, I. Deficiência mental: da superstição à ciência. São Paulo: EDUC/ TAQ, 1984

PLATÃO. Diálogos: a república. Carlos Alberto Nunes (Trad.). 2. ed. Belém: UFPa, 1988.

Rosadas, S. (de) C. Educação Física especial para deficientes. 3. ed. Rio de Janeiro: Atheneu, 1991.

SEMONIN, P. Monsters in the Marketplace: The Exibition of Human Oddities in Early Modern England, in GARLAND-THOMPSON, R (Org.). Freakery-Cultural Spetacles of the Extraordinary Body, New York, New York University Press, 1996.

STIKER, H. J. Corps infirmes et sociétés. Paris: Dunod, 2006.

Correspondência

Gustavo Martins Piccolo - Rua Alameda Estevo, n. 346, Centro, CEP 14813000, Gavião Peixoto, São Paulo, Brasil.

E-mail: gupiccolo@yahoo.com.br - egmendes@ufscar.br

Recebido em 16 de janeiro de 2012

Aprovado em 06 de março de 2012 